\title{
Three versions of Perceived Stress Scale: validation in a sample of Chinese cardiac patients who smoke
}

\author{
Doris YP Leung ${ }^{1}$, Tai-hing Lam², Sophia SC Chan ${ }^{1 *}$
}

\begin{abstract}
Background: Smoking causes heart disease, the major cause of death in China and Hong Kong. Stress is one major trigger of smoking and relapse, and understanding stress among smoking cardiac patients can therefore help in designing effective interventions to motivate them to quit. The objective of this study was to examine the psychometric properties of the Perceived Stress Scale (PSS), and to compare the appropriateness of the three versions of the scale (PSS-14, PSS-10, and PSS-4) among Chinese cardiac patients who were also smokers.

Methods: From March 2002 to December 2004, 1860 cardiac patients who smoked were recruited at the cardiac outpatient clinics of ten acute hospitals in Hong Kong, and 1800 questionnaires were analysed. Participants completed a questionnaire including the PSS, nicotine dependence and certain demographic variables. The psychometric properties of the PSS were investigated: construct validity using confirmatory factor analysis, reliability using Cronbach's alpha and concurrent validity by examining the relationship with smoking- and health-related variables.

Results: For all the three versions of the PSS, confirmatory factor analyses corroborated the 2-factor structure of the scale, with the positive and negative factors correlating significantly and negatively to a moderate extent $(r<$ -0.5), and high Cronbach's alpha values for the two subscales (alpha > 0.5). All the correlations of the two subscales and the smoking- and health-related variables were statistically significant and in the expected directions although of small magnitudes, except daily cigarette consumption.

Conclusions: The findings confirmed the satisfactory psychometric properties of all three Chinese versions of PSS. We recommend the use of PSS-10 for research which focuses on the two components of perceived stress, as it shows a higher reliability; and the use of PSS-4 if such partition is not essential and space for multiple measures is limited.
\end{abstract}

\section{Background}

Stress is a commonly reported trigger of smoking and relapse after quitting. Previous studies have shown that stress increases the amount of smoking, reduces the likelihood of successful quitting, and predicts relapse [1,2]. Higher stress is associated with less self-efficacy in quitting and less in not smoking among working adults [3], and less predicted success in quitting prospectively [4].

Heart disease is a leading cause of death in both China and Hong Kong [5,6]. Smoking is a modifiable

\footnotetext{
*Correspondence: nssophia@hkucc.hku.hk

'School of Nursing, The University of Hong Kong, LKS Faculty of Medicine Building, Pokfulam, Hong Kong

Full list of author information is available at the end of the article
}

health risk-factor for cardiac patients [7], but many of them continue to smoke regardless of the gain in health benefits from quitting including a reduction in both morbidity and mortality. There are calls for smoking cessation interventions which target smokers with high perceived stress levels [8]; this is particularly applicable to patients with chronic diseases who usually have high levels of perceived stress.

Cohen and colleagues developed the original 14-item English version of the Perceived Stress Scale (PSS-14) as a global measure of stress by asking respondents to report whether their lives seem to be unpredictable, uncontrollable or overloaded [9]. The PSS is one of the most frequently used tools to measure stress in chronic
C Biomed Central

C 2010 Leung et al; licensee BioMed Central Ltd. This is an Open Access article distributed under the terms of the Creative Commons Attribution License (http://creativecommons.org/licenses/by/2.0), which permits unrestricted use, distribution, and reproduction in any medium, provided the original work is properly cited. 
conditions and situations often not listed on other lifeevent scales, such as the Daily Hassles Scale [10] and Daily Stress Inventory [11]. The PSS is also available in two shortened versions of 10 items (PSS-10) and 4 items (PSS-4), with the items selected from the pool of 14 in the original version of PSS. The PSS is considered to be a brief scale measuring perceived stress that can be administered in a few minutes [12].

The scale has been translated into several languages, including Spanish, Swedish, Japanese and Chinese [13-16]. A few studies have examined the psychometric properties of the PSS, with five using principal component analysis (PCA) and three confirmatory factor analysis (CFA). The PCA studies provide important yet limited psychometric information on the PSS, as the statistical method has been criticised by methodologists [17]. Two CFA studies were conducted in clinical populations $[18,19]$ and one focused on college students [13], but mixed results on the structure of the PSS were reported. All the three CFA validation studies found a two-factor structure of the PSS, while others reported a one-factor structure, in particular for the 4-item version $[12,20]$. Moreover, it is unclear whether all the three versions of the PSS have a similar two-factor structure as well as relationships with certain variables.

The PSS has been applied extensively as a healthrelated outcome in studies examining the effect of smoking cessation interventions [21,22] and the Chinese version of the PSS has also been used in research areas such as mental health and physical activities [23,24]. Although the Chinese version of PSS was found to have high internal consistency and test-retest reliability, its construct and concurrent validity have not yet been established among smokers in Chinese societies, precluding the confident use of the instrument in this large population of varying cultures. The goals of the present study were to assess the construct validity, reliability and concurrent validity of the three versions of the Perceived Stress Scale (PSS), and to compare their appropriateness when used among Hong Kong Chinese cardiac patients who smoke.

\section{Methods}

\section{Participants}

The participants were the 1860 subjects of a randomised control trial investigating the effectiveness of a smoking cessation intervention among cardiac patients who smoked (Trial registration: http://www.isrctn.org Identifier: ISRCTN32840413). Chinese patients attending the cardiac outpatient clinics of 10 acute hospitals in Hong Kong were eligible if they had smoked at least one cigarette daily over the seven days prior to attendance. Ethical approval was obtained from the Ethics Committee of the Faculty of Medicine, University of Hong Kong and from the participating hospitals. Written consent was obtained from all participants. Recruitment was conducted from March 2002 to December 2004. Details of subject recruitment and the results of the study have been reported elsewhere [25]. Data were collected at baseline using a self-administered standardised and structured questionnaire, with a nurse helping to check for completeness. The sample consisted of 1693 men and 167 women, with a mean age of $58.3(\mathrm{SD}=14.1)$; the majority $(95.8 \%)$ had smoked daily over the past 30 days, with an average of daily consumption of 20 cigarettes $(S D=10)$. About half of the subjects (51.5\%) had coronary heart disease, and the other half had other heart problems such as congenital cardiac disease and arrhythmia.

\section{Measures}

The Perceived Stress Scale consists of 14 items (PSS-14) [9], seven positive and seven negative, and was translated into Chinese by the research team (see Additional file 1). Care was taken to ensure that each translated item retained a meaning as close as possible to the original version. The negative element is intended to assess lack of control and negative affective reactions, while the positive element measures the degree of ability to cope with existing stressors. Each item is rated on a five-point scale from $0=$ 'never' to $4=$ 'very often', covering the preceding month. The 10 -item version (PSS-10) consists of six negative and four positive items, while the 4-item version (PSS-4) has two items for each of the two factors.

The Fagerström Test of Nicotine Dependency (FTND) [26], with six questions, was used to measure nicotine dependency. Responses are summed to compute a score ranging from 0 to 10 . A higher FTND score indicates a greater degree of dependency. The Chinese version of FTND has been validated [27] and previously used in smoking cessation studies [28]. The Cronbach's alpha coefficient of FTND is 0.76 of the sample in the current study. We also assessed subjects' daily cigarette consumption over the past month, perceived health status over the past three months, confidence in not smoking again, and anxiety and depression at baseline. Each aspect was measured by a single item, with higher scores indicating better health, more confidence, more anxiety and more depression.

\section{Data analysis}

The factor structure of the three PSS versions was examined by confirmatory factor analysis of the 1800 subjects who completed the PSS. A one-factor model with all the items as indicators and a two-factor model with items corresponding to the positive and negative factors were fitted to the covariance matrix of the 
corresponding PSS items. The reliability of the scale was assessed by Cronbach's alpha, and concurrent validity was evaluated by correlations of the positive and negative PSS factors with FTND scores, daily cigarette consumption over the past month, and perceived health status, anxiety and depression. Furthermore, for each of the three versions of PSS, levels of stress were compared between males and females, using t-tests for the total scores and MANOVA for the scores of the positive and negative subscales simultaneously. Total stress scores were computed by first reversing the scores of the positive items and then summing all the items of the PSS. Sixty subjects left one or more items blank in the complete PSS version, and were excluded from the analysis.

All the CFAs were performed using EQS 6.0 and the maximum likelihood estimation method [29]. Model evaluations were made using a variety of fit indices, including the comparative fit index (CFI) [30], standardized root mean square residual (SRMR) [29], and the root mean square error of approximation (RMSEA) [31]. Values of CFI $>0.9$, SRMR $<0.08$, and RMSEA $<0.08$ are indicative of a good fit with the data [32]. Model chi-square test statistics and associated degrees of freedom and p-values were reported for completeness, although they were not used in model evaluation [33]. Cronbach's alpha, correlation, t-tests and MANOVA were computed using SPSS16.0. All statistical tests were two-tailed, and results were considered significant at $p<0.05$.

\section{Results}

\section{Confirmatory factor analysis}

Examination of the fit indexes in Table 1 reveals that the 2-factor models fitted well with PSS-10 and PSS-4 but only marginally with PSS-14, while the 1 -factor models did not provide acceptable fits with any of the three PSS versions. Table 2 presents the standardised factor loadings of the two-factor models for PSS-14, PSS-10 and PSS-4. For PSS-14, all standardised factor

Table 1 Results of confirmatory factor analyses of model testing of PSS-14, PSS-10 and PSS-4

\begin{tabular}{lcccccc}
\hline & $\chi^{\mathbf{2}}$ & df & p-value & CFI & RMSEA & SRMR \\
\hline PSS-14 & & & & & & \\
$\quad$ 1-factor model & 1341.7 & 77 & $<0.001$ & 0.747 & 0.096 & 0.096 \\
$\begin{array}{l}\text { 2-factor model } \\
\quad 557.2\end{array}$ & 76 & $<0.001$ & 0.904 & 0.059 & 0.059 \\
$\quad$ PSS-10 & & & & & & \\
1-factor model & 886.0 & 35 & $<0.001$ & 0.762 & 0.116 & 0.091 \\
$\quad$ 2-factor model & 198.9 & 34 & $<0.001$ & 0.954 & 0.052 & 0.048 \\
PSS-4 & & & & & & \\
$\quad$ 1-factor model & 80.9 & 2 & $<0.001$ & 0.900 & 0.147 & 0.068 \\
2-factor model & 7.0 & 1 & $<0.001$ & 0.992 & 0.014 & 0.057 \\
\hline
\end{tabular}

CFI = Comparative Fit Index; RMSEA = root mean square error of approximation; SRMR $=$ Standardised root mean square residuals. loadings were statistically significant and $>0.4$, except those associated with items 11 and 12 of the negative factor. Similar results were observed for PSS-10: all the standardised factor loadings were $>0.4$ except item 11 of the negative factor. For PSS-4, all four standardised factor loadings were $>0.4$. The two factors were statistically significant and correlated negatively, to a moderate extent, for all the three versions of PSS.

\section{Reliability analysis}

The coefficient alpha values for the positive and negative subscales were 0.86 and 0.77 for PSS-14, 0.83 and 0.76 for PSS-10, and 0.77 and 0.51 for PSS-4, respectively. All exceeded Kline's criterion of 0.7 for internal consistency [34], except in the case of the negative subscale of PSS-4. The Cronbach's alpha values of the full scales ranged from 0.67 for the PSS- 4 to 0.85 for PSS- 14 . Scores on the positive and negative subscales were computed by averaging the corresponding items for PSS-14, PSS-10, and PSS-4 in each case; higher scores on negative and positive subscales indicate higher levels of perceived distress and coping ability, separately. Overall scores for the three versions of PSS then were computed by adding the negative and the reverse of the positive subscale scores.

\section{Concurrent validity}

As shown in Table 3, the positive subscale correlated negatively with FTND scores and levels of anxiety and depression, and positively with daily cigarette consumption and perceived health; while the negative subscale showed an opposite direction of the correlations with these variables. The pattern of correlations for the three overall PSS scores was similar to that of the negative subscales. For all three versions of the PSS, all correlations were statistically significant and in the expected direction, with one exception: daily cigarette consumption correlated significantly and positively with the positive factor, but negatively with the negative factor, although the correlation was non-significant. In general, compared with the positive factor, the correlations of the negative factor were larger with health-related variables, similar with FTND scores and smaller with confidence in not smoking again and daily cigarette consumption.

\section{Comparison of stress level by sex}

Table 4 shows the descriptive, t-test and MANOVA results of the sex effect on perceived stress levels, as measured by PSS-14, PSS-10 and PSS-4. Women reported a significantly higher total mean score on perceived stress than men. In addition, women scored both significantly higher in the negative subscale and lower in the positive subscale than men, irrespective of the PSS version. 
Table 2 Standardised factor loadings of the 2-factor models fitted to PSS-14, PSS-10 and PSS-4

\begin{tabular}{|c|c|c|c|c|c|c|c|}
\hline \multirow[b]{2}{*}{ Item } & & \multicolumn{2}{|c|}{ PSS-14 } & \multicolumn{2}{|c|}{ PSS-10 } & \multicolumn{2}{|c|}{ PSS-4 } \\
\hline & & Negative & Positive & Negative & Positive & Negative & Positive \\
\hline 1 & upset by something happening unexpectedly? & .76 & 0 & .77 & 0 & - & - \\
\hline 2 & unable to control the important things in your life? & .81 & 0 & .82 & 0 & .74 & 0 \\
\hline 3 & nervous and stressed? & .79 & 0 & .78 & 0 & - & - \\
\hline 8 & could not cope with all the things that you had to do? & .44 & 0 & .44 & 0 & - & - \\
\hline 11 & angered because of things that happened that were outside your control? & .27 & 0 & .26 & 0 & - & - \\
\hline 12 & thinking about things that you have to accomplish? & .34 & 0 & - & - & - & - \\
\hline 14 & difficulties were pilling up so high that you could not overcome them? & .44 & 0 & .44 & 0 & .46 & 0 \\
\hline 4 & dealt successfully with day-to-day problems and annoyances? & 0 & .64 & - & - & - & - \\
\hline 5 & effectively coping with important changes that were occurring in your life? & 0 & .66 & - & - & - & - \\
\hline 6 & confident about your ability to handle your personal problems? & 0 & .79 & 0 & .77 & 0 & .73 \\
\hline 7 & things were going your way? & 0 & .72 & 0 & .77 & 0 & .86 \\
\hline 9 & dealt successfully with irritating life hassles? & 0 & .66 & 0 & .63 & - & - \\
\hline 10 & you were on top of things? & 0 & .74 & 0 & .78 & - & - \\
\hline \multirow[t]{4}{*}{13} & able to control the way you spend your time? & 0 & .56 & - & - & - & - \\
\hline & Factor correlation & \multicolumn{2}{|c|}{-.54} & \multicolumn{2}{|c|}{-.57} & \multicolumn{2}{|c|}{-.58} \\
\hline & Cronbach alpha & .77 & .86 & .76 & .83 & .51 & .77 \\
\hline & & \multicolumn{2}{|c|}{.85} & \multicolumn{2}{|c|}{.83} & \multicolumn{2}{|c|}{67} \\
\hline
\end{tabular}

\section{Discussion}

This study has explored and extended the factor structure of the Chinese version of the Perceived Stress Scale and its shorter variants (PSS-10 and PSS-4) from clinic populations in the West to a Chinese cardiac population with a smoking habit. The results show that construct validity, internal consistency and concurrent validity of the Chinese versions of PSS-14, PSS-10 and PSS-4 and their corresponding subscales were generally supported in a community-based sample of Chinese smoking adults with cardiac disease.
Our study provides evidence to support the manifestation of the PSS as two-dimensional, and that the twofactor models give better approximations of the data of PSS-14, PSS-10 and PSS-4 with items loaded on their designated factor. The results obtained are consistent with previous CFA studies using PSS-14 and PSS-12 $[13,18,19]$, but contrary to those using PSS-4, which was hypothesised as one latent factor $[12,20]$. The factor loading of item 11 of the negative factor was found in the present study to be far below 0.4 in both PSS-14 (0.27) and PSS-10 (0.26). The low factor loadings of this

Table 3 Correlations of subscale scores on PSS-14, PSS-10 and PSS-4 and smoking and health related variables

\begin{tabular}{|c|c|c|c|c|c|c|c|c|c|}
\hline & \multicolumn{3}{|c|}{ PSS-14 } & \multicolumn{3}{|c|}{ PSS-10 } & \multicolumn{3}{|c|}{ PSS-4 } \\
\hline & $\begin{array}{l}\text {-ve } \\
\text { Factor }\end{array}$ & $\begin{array}{l}\text { +ve } \\
\text { Factor }\end{array}$ & Overall & $\begin{array}{l}\text {-ve } \\
\text { Factor }\end{array}$ & $\begin{array}{l}\text { +ve } \\
\text { Factor }\end{array}$ & Overall & $\begin{array}{l}\text {-ve } \\
\text { Factor }\end{array}$ & $\begin{array}{l}\text { +ve } \\
\text { Factor }\end{array}$ & Overall \\
\hline \multicolumn{10}{|l|}{ Smoking-related variables } \\
\hline $\begin{array}{l}\text { Daily cigarette consumption in the past } \\
\text { month }\end{array}$ & -.04 & $.09^{* *}$ & .01 & -.03 & $.09 * *$ & .03 & .00 & $.08^{* *}$ & $.05^{*}$ \\
\hline FTND score ${ }^{1}$ & $.10^{* *}$ & $-.09 * *$ & $.11^{* *}$ & $.10^{* *}$ & $-.10^{* *}$ & $.11^{* *}$ & $.07^{*}$ & $-.11^{* *}$ & $.10^{* *}$ \\
\hline Confidence in not smoking again ${ }^{2}$ & $-.14^{* *}$ & $.20^{* *}$ & $-.19^{* *}$ & $-.13^{* *}$ & $.23^{* *}$ & $-.19^{* *}$ & $-.91^{* *}$ & $.21^{* *}$ & $-.18^{* *}$ \\
\hline \multicolumn{10}{|l|}{ Health-related variables } \\
\hline $\begin{array}{l}\text { Perceived health status in the past } 3 \\
\text { months }^{3}\end{array}$ & $-.15^{* *}$ & $.11^{* *}$ & $-.16^{* *}$ & $-.16^{* *}$ & $.12^{* *}$ & $-.17^{* *}$ & $-.17^{* *}$ & $.13^{* *}$ & $-.19^{* *}$ \\
\hline Anxiety today ${ }^{4}$ & $.21^{* *}$ & $-.10^{* *}$ & $.18^{* *}$ & $.20^{* *}$ & $-.12^{* *}$ & $.19^{* *}$ & $.19^{* *}$ & $-.13^{* *}$ & $.19^{* *}$ \\
\hline Depression today ${ }^{5}$ & $.22^{* *}$ & $-.16^{* *}$ & $.22^{* *}$ & $.23^{* *}$ & $-.19^{* *}$ & $.24^{* *}$ & $.22^{* *}$ & $-.19 * *$ & $.24^{* *}$ \\
\hline
\end{tabular}

${ }^{1}$ FTND scores range from 0 to 10 , with higher values indicating higher levels of nicotine dependency.

${ }^{2}$ Confidence in not smoking again was measured with a scale from 0-100, with higher values indicating higher levels of confidence

${ }^{3}$ Perceived health status was measured on a 4-point Likert scale, with higher values indicating better perceived health.

${ }^{4}$ Anxiety was measured on a 3-point Likert scale, with higher values indicating higher levels of anxiety.

${ }^{5}$ Depression was measured on a 3-point Likert scale, with higher values indicating higher levels of depression.

* $\mathrm{p}$-value $<0.05{ }^{* *} \mathrm{p}$-value $<0.01$ 
Table 4 Means of total and subscale scores on PSS-14, PSS-10 and PSS-4 by sex

\begin{tabular}{|c|c|c|c|c|c|}
\hline \multirow[b]{2}{*}{ Variable } & \multicolumn{2}{|c|}{ Men $(n=1634)$} & \multicolumn{2}{|c|}{ Women $(n=166)$} & \multirow[b]{2}{*}{ p-value ${ }^{1}$} \\
\hline & Mean & SD & Mean & SD & \\
\hline \multicolumn{6}{|l|}{ PSS-14 } \\
\hline Total & 22.3 & 5.7 & 23.6 & 6.0 & 0.006 \\
\hline Positive subscale & 15.6 & 3.4 & 14.9 & 3.3 & 0.021 \\
\hline Negative subscale & 9.9 & 3.3 & 10.3 & 3.7 & \\
\hline \multicolumn{6}{|l|}{ PSS-10 } \\
\hline Total & 15.2 & 4.4 & 16.3 & 4.8 & 0.003 \\
\hline Positive subscale & 8.9 & 2.1 & 8.5 & 2.0 & 0.010 \\
\hline Negative subscale & 8.1 & 3.0 & 8.7 & 3.5 & \\
\hline \multicolumn{6}{|l|}{ PSS-4 } \\
\hline Total & 6.0 & 2.0 & 6.5 & 2.1 & 0.007 \\
\hline Positive subscale & 4.4 & 1.2 & 4.3 & 1.2 & 0.014 \\
\hline Negative subscale & 2.5 & 1.2 & 2.7 & 1.3 & \\
\hline
\end{tabular}

${ }^{1}$ T-tests used for comparing mean differences in the total score, and MANOVA for comparing mean differences in the positive and negative subscale scores simultaneously.

item compared with the rest of the negative factor could be due to the potential interpretation of 'anger' as expressing the perceived distress externally by the subjects. Alternatively, it could simply have been produced by the translation process but we could not find any study utilizing the Chinese PSS reporting the associated factor loadings for comparison and hence more studies are needed to verify this possibility. Indeed, a low factor loading of 0.28 for item 7 has also been reported among a sample of ambulatory care patients with asthma in the US [19]. Future studies are warranted to address equivalence in items of the PSS across sub-populations such as sex, ethnicity and education.

Cronbach's alpha values demonstrate that each of the two subscales of PSS-14 and PSS-10 are internally reliable and form a cohort set of the construct. Similar to previous studies conducted in the Asian region, including Japan, Singapore and Taiwan $[24,35,36]$, high internal consistency reliability of the three overall scales of the PSS was also observed in the current study. Although the alpha value of this subscale of PSS- 4 was below the cut-off point of 0.7 , it has been argued that a reliability coefficient as low as 0.5 should not seriously attenuate validity [37] and the alpha coefficient increases with the instrument's length [38]; this subscale is therefore still considered reliable.

The subscales of the PSS correlate with smoking- and health-related variables in the anticipated directions except daily cigarette consumption, providing some preliminary evidence on the concurrent validity of the PSS scale in the three versions. Our results on the low correlations of the PSS with smoking-related variables were consistent with previous studies that low and insignificant correlations of the PSS scores with other smoking-related variables were also reported in Cohen and Lichtenstein's study among smokers [1]. In the large community-based study in the US, high stress was significantly associated with reports of increased tobacco consumption and less confidence in not smoking again but the magnitude of the association was also small after controlled for demographic variables [3]. Results from our study and the two previous studies show that PSS is associated with smoking-related variables but it might not act as a proxy for them.

The opposite correlations of the positive and negative factors of PSS with these variables provide further evidence of the manifestation of two components in PSS. The greater correlations with 'perceived distress' than with 'perceived coping' support the assertion that individuals react to a stressor or threatening event with a primary appraisal, and judge their ability to cope with the stressor or event with a secondary appraisal in the stress and coping model [39]. Further research will need to test the differential predictive validity of the two PSS subscales.

Consistent with earlier findings [40,41], we have also found that women reported a significant higher total score for perceived stress. In addition, we have found women had significantly higher scores in the negative and lower scores in the positive subscales than men, regardless of the PSS version. This result is also consistent with previous findings, that women smoke more for tension reduction and relaxation $[42,43]$.

Our results show that the psychometric properties of all three versions are satisfactory and similar. However, it is important to consider which version of the PSS should be used in particular applications. As in a previous study [40], the PSS-10 not only provides an adequate measure of perceived stress and similar correlations with smokingand health-related measures as the complete version, but has also shown a higher reliability among our Chinese patients. In addition, the PSS-4 also has satisfactory construct validity, but a somewhat lower reliability in the negative subscale. From a practical point of view, because a shorter questionnaire would be more appropriate for studies with multiple measures, we recommend the use of PSS-10 in future research to focus on the two components of perceived stress; and the use of PSS-4 if such separation is not essential and space for multiple measures is limited [44].

This study had several limitations. First, the present validation study of the PPS was part of a randomised controlled trial carried out among a group of cardiac outpatients who smoke. Given the large sample size, our results can be generalised to smoking cardiac patients, but not to those who do not smoke. Moreover, the large proportion of male participants in the study may limit its generalisability to female smokers. However, the potential of the current findings to be generalised is 
enormous, given that smoking in Hong Kong and elsewhere in Asia is strongly sex-linked with much higher smoking prevalence in men (men $>40 \%$, women $<10 \%$ ) [45] and that cardio-vascular disease is the number one killer in China [6]. Nevertheless, further research using population-based study and on different subgroups among the Chinese and other Asian populations is warranted. Second, the use of single-item measures of smoking and health-related variables in the study (except FTND) should include a substantial amount of measurement error in each of these variables. The imperfect measures of these variables however would lead to underestimation of the correlations with other variables, which could explain the low observed correlations with the PSS scores [46]. Third, we were unable to assess test-retest reliability of the PSS in the current study as it was a secondary data analysis of an RCT and such information were not collected at follow-up surveys. Further studies on the psychometric properties of the Chinese versions of the PSS should be carefully designed to include both precise measures of potential related variables to assess concurrent validity and a testretest component to examine stability of the instrument.

\section{Conclusion}

The study corroborates the observations of others in demonstrating that the Chinese-translated PSS has adequate construct validity, reliability and concurrent validity, and hence is acceptable in a clinical smoking population with cardiac disease. Researchers may choose the shorter versions of PSS (PSS-10 and PSS-4) depending on the practical needs of their work.

\section{Additional material}

Additional file 1: The Chinese version of the Perceived Stress Scale Chinese translation of the 14 items in the Perceived Stress Scale.

\section{Acknowledgements}

The original clinical trial study was supported by a Competitive Earmarked Research Grant (CERG) from the Research Grants Council, Hong Kong (HKU7224/01 M). Part of the study was presented at the $8^{\text {th }}$ Asia Pacific Conference on Tobacco or Health in Taipei, October 17-20 2007.

\section{Author details}

${ }^{1}$ School of Nursing, The University of Hong Kong, LKS Faculty of Medicine Building, Pokfulam, Hong Kong. '2Department of Community Medicine, School of Public Health, The University of Hong Kong, LKS Faculty of Medicine Building, Pokfulam, Hong Kong.

\section{Authors' contributions}

$\mathrm{DL}$ performed the statistical analysis, interpreted the results and drafted the manuscript. THL participated in the design of the study, and helped to draft and revise the manuscript. SC participated in both design and coordination, and helped to draft and revise the manuscript. All authors reviewed and approved the manuscript.

\section{Competing interests}

The authors declare that they have no competing interests.

Received: 16 April 2010 Accepted: 25 August 2010

Published: 25 August 2010

\section{References}

1. Cohen S, Litchtenstein E: Perceived stress, quitting smoking, and smoking relapse. Health Psychol 1990, 9(4):466-478.

2. Shiffman S, Hickox M, Paty JA, Gnys M, Richards T, Kassel JD: Individual differences in the context of smoking lapse episodes. Addict Behav 1997, 22:797-811.

3. Ng DM, Jeffery R: Relationship between perceived stress and health behaviors in a sample of working adults. Health Psychol 2003, 22(6):638-642.

4. Glasgow RE, Klesges RC, Mizes JS, Pechacek TF: Quitting smoking: strategies used and variables associated with success in a stop smoking contest. J Consult Clin Psych 1985, 53:905-912.

5. Department of Health: Health Facts of Hong Kong 2008 Edition. 2008 [http://www.dh.gov.hk/english/statistics/statistics_hs/files/ Health_Statistics_pamphlet_2008e.pdf].

6. World Health Organization: Preventing chronic diseases: A vital investment. World Health Organization Global Report 2005 [http://www. who.int/chp/chronic_disease_report/en/].

7. U.S. Department of Health and Human Services: The Health Consequences of Smoking: A Report of the Surgeon General Atlanta, GA: U.S. Department of Health and Human Services, Centers for Disease Control and Prevention, National Center for Chronic Disease Prevention and Health Promotion, Office on Smoking and Health 2004

8. Siqueira LM, Rolnitzky LM, Rickert VI: Smoking cessation in adolescents: the role of nicotine dependence, stress, and coping methods. Arch Pediat Adol Med 2001, 155:489-495.

9. Cohen S, Kamarak T, Mermelstein R: A global measure of perceived stress. J Health Soc Behav 1983, 24:385-396.

10. Kanner AD, Coyne JC, Schaefer C, Lazarus RS: Comparison of two modes of stress measurement: Daily hassles \& uplifts versus major life events. J Behav Med 1981, 17:1-23.

11. Brantley PJ, Jones GN: Daily Stress Inventory Psychological Assessment Resources Inc., Florida, USA 1989.

12. Cohen S, Williamson G: Perceived stress in a probability sample of the United States. In The Social Psychology of Health. Edited by: Spacapan S, Oskamp S. Newbury Park, CA: Sage; 1988:31-68.

13. Ramírez MTG, Hernández RL: Factor structure of the Perceived Stress Scale (PSS) in a sample from Mexico. The Spanish Journal of Psychology 2007, 10(1):199-206.

14. Eskin M, Parr D: Introducing a Swedish version of an instrument measuring mental stress Reports from the Department of Psychology, U Stockholm 813 1996, 1-9.

15. Mimura C, Griffiths P: A Japanese version of the perceived stress scale: translation and preliminary test. Int J Nurs Stud 2004, 41:379-385.

16. Lee S, Crockett MS: Effect of assertiveness training on levels of stress and assertiveness experienced by nurses in Taiwan, Republic of China. Issues Mental Health Nursing 1994, 15:419-432.

17. Byrne BM: Factor analytic models: Viewing the structure of an assessment instrument from three perspectives. Journal of Personality Assessment 2005, 85:17-32.

18. Golden-Kreutz DM, Frierson GM, Anderson BL: Assessing stress in cancer patients: A second-order factor analysis model for the Perceived Stress Scale. Assessment 2004, 11:216-223.

19. Sharp LK, Kimmel LG, Kee $R$, Saltoun $C$, Chang CH: Assessing the Perceived Stress Scale for African American adults with asthma and low literacy. $J$ Asthma 2007, 44:311-316.

20. Herrero J, Meneses J: Short web-based versions of the perceived stress (PSS) and Center for Epidemiological Studies-Depression (CESD) Scales: a comparison to pencil and paper responses among internet users. Comput Hum Behav 2006, 22:830-846.

21. Prochaska JJ, Hall SM, Humfleet G, Muňoz RF, Reus V, Gorecki J, Hu D: Physical activity as a strategy for maintaining tobacco abstinence: a randomized trial. Prev Med 2008, 47(2):215-220. 
22. Ames SC, Patten CA, Werch CE, Schroeder DR, Stevens SR, Fredrickson PA, Echols JD, Pennebaker JW, Hurt RD: Expressing writing as a smoking cessation treatment adjunct for young adults smokers. Nicotine Tob Res 2007, 9(2):185-194

23. Chu L-C, Kao HSR: The moderation and meditation experience and emotional intelligence on the relationship between perceived stress and negative mental health. Chinese Journal of Psychology 2005, 47(2):157-179.

24. Taylor-Piliae RE, Haskell WL, Waters CM, Froelicher ES: Change in perceived psychosocial status following a 12-week Tai Chi exercise programme. J Adv Nurs 2006, 54(3):313-329.

25. Chan SSC, Chan SC, Lau CP, Lam TH: The effectiveness of a stagematched smoking cessation intervention for cardiac patients: a randomized controlled trial. Paper presented at 13th World Conference on Tobacco OR Health: Building capacity of a tobacco-free world: 12-15 July 2006; Washington, D.C., U.S.A [http://2006.confex.com/uicc/wctoh/techprogram/ P8926.HTM]

26. Heatherton TF, Kozlowski LT, Frecker RC, Fagerström KO: The Fagerström test for nicotine dependence: a revision of the Fagerström tolerance questionnaire. British Journal of Addiction 1991, 6:1119-1127.

27. Huang $\mathrm{C}-\mathrm{L}$, Lin $\mathrm{H}-\mathrm{H}$, Wang $\mathrm{H}-\mathrm{H}$ : The psychometric properties of the Chinese version of the Fagerstrom Test for Nicotine Dependence. Addict Behav 2006, 31(12):2324-2327.

28. Lam TH, Abdullah ASM, Chan SSC, Hedley A, Hong Kong Council on Smoking and Health Smoking Cessation Health Centre (SCHS) Steering Group: Adherence to nicotine replacement therapy versus quitting smoking among Chinese smokers: a preliminary investigation. Psychopharmacology 2005, 177:400-408.

29. Bentler PM: EQS 6.0 Structural Equations Program Manual Encino, CA: Multivariate Software 2006.

30. Bentler PM: Comparative fit indexes in structural models. Psychol Bull 1990, 107:238-246.

31. Steiger JH: Structural model evaluation and modification: An interval estimation approach. Multivar Behav Res 1990, 25:173-180.

32. Hoyle RH: The structural equation modeling approach: Basic concepts and fundamental issues. In Structural equation modeling, concepts, issues, and applications. Edited by: Hoyle RH. Thousand Oaks, CA: Sage; 1995:1-15.

33. Beckstead JW, Yang CY, Lengacher CA: Assessing cross-cultural validity of scales: a methodological review and illustrative example. Int I Nurs Stud 2008, 45:110-119.

34. Kline P: A psychometrics primer London: Free Association Books 2000.

35. Mimura C, Griffiths P: A Japanese version of the Perceived Stress Scale: cross-cultural translation and equivalence assessment. BMC Psychiatry 2008, 8:85.

36. Lok CF, Bishop GD: Emotion control, stress, and health. Psychology and Health 1999, 14:813-827.

37. Schmitt M: Uses and abuse of coefficient alpha. Psychol Assessment 1996, 8:350-353.

38. Miller MB: Coefficient alpha: a basic introduction from the perspectives of classical test theory and structural equation modelling. Struct Equ Modeling 1995, 2:255-273.

39. Folkman S: Positive psychological states and coping with severe stress. Soc Sci Med 1997, 45:1207-1221.

40. Remor E: Psychometric properties of a European Spanish version of the Perceived Stress Scale (PSS). The Spanish Journal of Psychology 2006, 9(1):86-93.

41. Wong JGWS, Cheung EPT, Cheung V, Cheung C, Chan MTY, Chua SE, McAlonan GM, Tsang KWT, Ip MSM: Psychological responses to the SARA outbreak in healthcare students in Hong Kong. Medical Teacher 2004, 26(7):657-663.

42. Berlin I, Singleton EG, Pedarriosse AM, Lancrenon S, Rames A, Aubin HJ, Niaura R: The Modified Reasons for Smoking Scale: factorial structure, gender effects and relationship with nicotine dependence and smoking cessation in French smokers. Addition 2003, 98:1575-1583.

43. Ho SY, Lai MK, Lam TH: Youth Smoking Survey 2003/4: Report on the crosssectional and prospective study Report submitted to the Hong Kong Council on Smoking and Health and the Department of Health, Hong Kong Special Administrative Region 2005.

44. Littman AJ, White E, Satia JA, Bowen DJ, Kristal AR: Reliability and validity of 2 single-item measures of psychosocial stress. Epidemiology 2006, 17(4):398-403.
45. Mackay J, Eriksen M, Shafey O: The Tobacco Atlas Georgia, Atlanta: American Cancer Society, 22006.

46. Hausman JA: Mismeasured variables in econometric analysis: problems from the right and problems from the left. J Econ Perspect 2001, 15(4):57-67.

\section{Pre-publication history}

The pre-publication history for this paper can be accessed here: http://www.biomedcentral.com/1471-2458/10/513/prepub

doi:10.1186/1471-2458-10-513

Cite this article as: Leung et al:: Three versions of Perceived Stress Scale: validation in a sample of Chinese cardiac patients who smoke. BMC Public Health 2010 10:513.

\section{Submit your next manuscript to BioMed Central and take full advantage of:}

- Convenient online submission

- Thorough peer review

- No space constraints or color figure charges

- Immediate publication on acceptance

- Inclusion in PubMed, CAS, Scopus and Google Scholar

- Research which is freely available for redistribution

Submit your manuscript at www.biomedcentral.com/submit
C) Biomed Central 